\title{
Several Chinese herbal products may contain toxic aristolochic acid
}

Reason for posting: Aristolochic acid, a naturally occurring herbal toxin that can cause cancer and end-stage kidney failure, has been the subject of warnings since 1999 from several international regulatory agencies. Canadian manufacturers, importers and retailers were directed in 2001 to remove all herbal products containing aristolochic acid from their shelves. ${ }^{1}$ However, Health Canada recently reissued a warning that consumers avoid such products ${ }^{2}$ amid concerns that the products are still widely available through the Internet. ${ }^{3}$ The Hong Kong Department of Health also recently published a list of specific brands of Chinese medicines known to contain aristolochic acid that should not be consumed (available in an online appendix at www.cmaj .ca/cgi/content/full/171/5/449 /DC1).

The drug: Evidence of aristolochic acid's toxicity in animals has accumulated since the 1980s. Its toxicity in humans re- ceived widespread attention 4 years ago when a case series was published describing urinary tract cancers, nephropathy and renal failure in more than 100 women in Belgium who had taken weight-reducing pills containing aristolochic acid. ${ }^{4}$ Aris- tolochic acid, which is among the most potent $2 \%$ of carcinogens known, ${ }^{3}$ is derived principally from plants of the genus Aristolochia but may also be found in products containing several other botanicals (Box 1). Natural health products containing aristolochic acid are often sold as traditional Chinese medicines meant to effect weight loss, improve the immune system or alleviate gastrointestinal symptoms, menstrual complaints, cough and allergies. As with most herbal products, there is little and often no evidence from clinical trials of their efficacy for any of these benefits. No adverse effects related to aristolochic acid exposure have yet been reported in Canada.

What to do: Language barriers may prevent many health care practitioners from effectively verifying the ingredients listed on many Chinese herbal products. Instead, patients using Chinese herbal products should be warned to ensure that the products they are using do not contain the ingredients in question (Box 1) and are not one of the brands that have been recalled (see online appendix). $\mathrm{Pa}$ tients with suspected exposure to aristolochic acid should be monitored for signs of urinary tract tumours and nephropathy.

Eric Wooltorton

CMA7

\section{References}

1. Health Canada advises consumers about additional products that could contain aristolochic acid. Ottawa: Health Canada; 2001 Oct 5. Available: www.hc-sc.gc .ca/english/protection/warnings/2001 /2001_105e.htm (accessed 2004 Aug 5).

2. Health Canada advises consumers not to use the products containing aristolochic acid. Ottawa: Health Canada; 2004 July 26. Available: www.hc-sc.gc.ca /english/protection/warnings/2004/2004 43.htm (accessed 2004 Aug 5).

3. Gold LS, Slone TH. Aristolochic acid, an herbal carcinogen, sold on the Web after FDA alert [letter]. $N$ Engl 7 Med 2003;349:1576-7.

4. Nortier JL, Martinez MC, Schmeiser $\mathrm{HH}$, Arlt VM, Bieler CA, Petein M, et al. Urothelial carcinoma associated with the use of a Chinese herb (Aristolochia fangchi). N Engl 7 Med 2000; 342:1686-92.

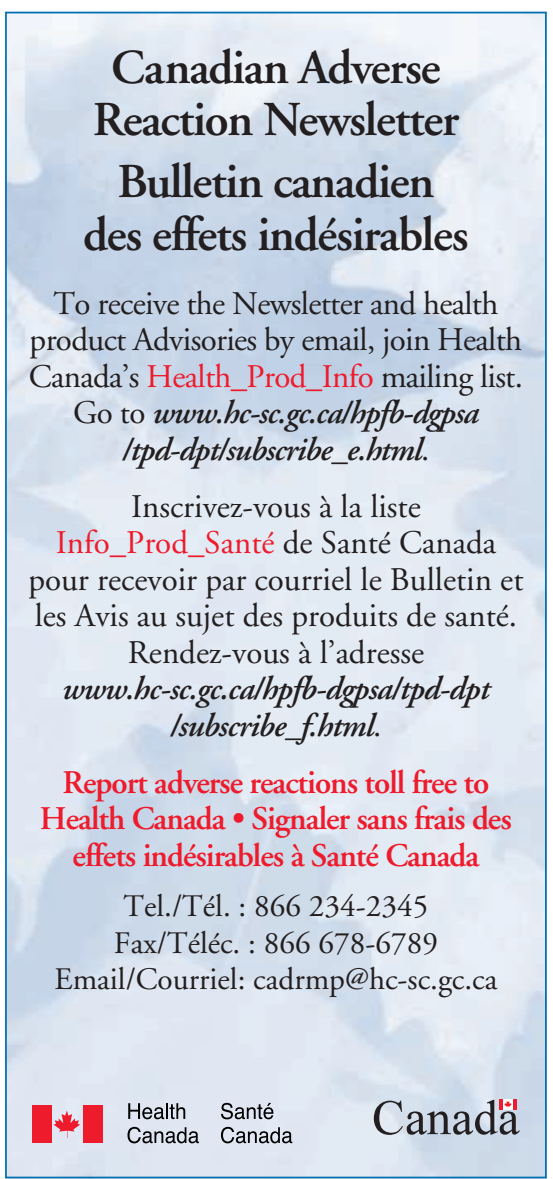

Box 1: Chinese herbal products containing the following botanicals could contain Aristolochia and its toxic derivative aristolochic acid

$\begin{array}{ll}\text { Akebia } & \text { Menispermum } \\ \text { Asarum* } & \text { Mu Tong } \\ \text { Bragantia* } & \text { Sinomenium } \\ \text { Clematis } & \text { Saussurea } \\ \text { Cocculus } & \text { Stephania } \\ \text { Diploclisia } & \text { Vladimiria }\end{array}$

*Asarum (wild ginger, unrelated to common ginger) and Bragantia (also known as Apama or Thottea) are plants known to contain aristolochic acid. 